\title{
Health behaviour of postmenopausal women after mastectomy - preliminary study
}

\author{
Anna B. Pilewska-Kozak', Beata B. Dobrowolska², Celina Łepecka-Klusek', Grażyna Stadnicka³, \\ Lechosław Putowski', Justyna Malesa ${ }^{4}$, Alvisa Palese ${ }^{5}$ \\ ${ }^{1}$ Chair and Department of Gynaecology and Gynaecological Endocrinology, Faculty of Health Sciences, Medical \\ University, Lublin, Poland \\ ${ }^{2}$ Chair of Development in Nursing, Faculty of Health Sciences, Medical University, Lublin, Poland \\ ${ }^{3}$ Department of the Basics of Midwifery, Faculty of Health Sciences, Medical University, Lublin, Poland \\ ${ }^{4}$ Student Faculty of Health Sciences, Medical University, Lublin, Poland \\ ${ }^{5}$ University of Udine, Italy
}

Pilewska-Kozak A. B, Dobrowolska B. B, Łepecka-Klusek C, Stadnicka G, Putowski L, Malesa J, Palese A. Health behaviour of postmenopausal women after mastectomy - preliminary study. J Pre-Clin Clin Res. 2018; 12(2): 45-50. doi: 10.26444/jpccr/89870

\section{Abstract}

Introduction. A sample of 95 Polish postmenopausal women after mastectomy were studied with the objective of describing Health Behaviour Indicators (HBIs) among the participants. The notion of health, the subjective evaluation of the participants' health condition and their lifestyle before cancer diagnosis and at present wewre examined.

Materials and method. Two data collection instruments were used: a questionnaire developed by the research team, and the Health Behaviour Inventory (HBI) - a standardised questionnaire developed by Juczyński. The HBIs four main dimensions: proper nutritional habits (PNH), preventive behaviours (PB), health practices (HPs), and positive mental attitude (PMA) were examined. One-way analysis of variance (ANOVA) was performed with the post-hoc test (multiple comparisons conducted Turkey's test).

Results. Well-being was the most often indicated description of the health notions of the women surveyed. The majority of women $(75 ; 78.9 \%)$ believed that they led a healthy lifestyle. The overall HBI, on average, was 85.7 out of 120 . Specifically, HPs was the highest health behaviour enacted (3.75 Standard Deviation [SD] 1.59), followed by PB (3.66; 0.69 SD). In the bivariate analysis, married $(87.2 ; 12.7 \mathrm{SD})$ and widowed $(89.8 ; 7.9 \mathrm{SD})$ women reported higher scores than those who were unmarried $(76.7 ; 14.6 \mathrm{SD})$ and divorced $(83.6 ; 12.5 \mathrm{SD})(\mathrm{p}<0.05)$.

Conclusions. $\mathrm{HBI}$ of postmenopausal women after mastectomy is high, which may suggest that mastectomy at the postmenopausal state enforces pro-healthy HBs.

\section{Key words}

breast cancer, mastectomy, menopause, women, health behaviours, health notion

\section{INTRODUCTION}

Preventive interventions against breast cancer are limited as the aetiology of the disease has not been thoroughly understood. Early detection through screening strategies are therefore strongly recommended, given that these have been associated with good prognosis and longer survival $[1,2,3]$.

In Poland, breast cancer is diagnosed most frequently in women between the ages of 50-69, although its occurrence among younger women is increasing. At present, almost 25\% of oncological diagnoses in Polish women concern breast cancer (22.8\%), and almost 70,000 people are living with this type of cancer, diagnosed in the last 5 years. Every year there are more than 16,500 new cases being diagnosed [1] and [3] and it has recently been anticipated that in the next 10 years the number of patients will increase and exceed 20,000 new cases annually [2]. Negative effects are reported not only on the lives of individuals and their families, but also on the economy of health care and economic phenomena in a broader sense [4]. Therefore, identifying factors that influence the effectiveness of treatment on the quality of life and life

Adress for correspondence: Dr. Anna B. Pilewska-Kozak, Chair and Department of Gynecology and Gynecological Endocrinology, Faculty of Health Sciences, Medical University of Lublin, Poland

E-mail: apilewska@poczta.wp.p

Received: 26 February.2018; accepted: 11 April 2018 expectancy of women suffering from breast cancer, included their capacity to maintain previous social and professional activity, should be taken into account in oncological health priorities.

Breast cancer treatment is complex and long-term. Following mastectomy, patients fear a recurrence of the disease, or even death. Indeed, it has been reported that after mastectomy the majority of woman radically change their lifestyles and try to avoid negative health behaviours, placing greater emphasis on behaviours with a positive impact on health, such as paying attention to optimal diet, sleep duration, recreation, and physical activity. However, they struggle to give up smoking, drinking strong coffee or tea, while they check their health and carefully look for any changes that might occur $[3,5-13]$.

A number of studies concerning the life style of women at different stages of breast cancer has been documented to date, and some of these have analysed changes in health behaviour (HB) after mastectomy; for example, Polish studies [3, 5] and [7] as well as other studies [13, 14] and [15]. However, to the best of the authors' knowledge, no studies have focused on health behaviour among postmenopausal women after mastectomy. First, in these patients, health behaviour (e.g. nutrition, physical activity) may affect the occurrence of some health problems (e.g. obesity, osteoporosis or breast cancer itself). Second, these patients are expected to present more 
pro-healthy behaviours aimed at preventing risks $[16,17]$. Studying health behaviours (HBs) enacted by this population, can help to identify weaknesses and thus strengthen and tailor health promoting interventions.

\section{OBJECTIVE}

The principal aim of this study was to explore Health Behavior Indicators (HBIs) among postmenopausal women after mastectomy. Secondary aims were to describe the notion of health, the subjective evaluation of the participant's health condition, and their lifestyle before the cancer diagnosis and at present.

\section{MATERIALS AND METHOD}

The Bioethical Commission of the Medical University in Lublin, eastern Poland, approved the research protocol (KE0254/179/2013, dated 20 June 2013). A descriptive study was used including a convenience sample of 95 women affiliated with the Amazon Women Association in the city of Lublin. Women were eligible to participate in the study if: (a) they had undergone surgery $>3$ months prior to recruitment into the study and had reported $>12$ months of menopause; (b) they had been followed-up by the oncological clinic of St. John's Oncology Centre in Lublin; and (c) they were willing to participate in the study. Participation in the study was voluntary and anonymous. Of the 104 women approached, 9 did not agree to participate in the study without giving any reason.

Two data collection instruments were used: (1) a questionnaire developed by the research team, and (2) the Health Behavior Inventory (HBI) - a standardised questionnaire developed by Juczyński, purchased in the Psychological Test Laboratory of the Polish Psychological Association [18]. The first questionnaire consists of 2 parts: socio-demographic variables and questions regarding the notion of health, as well as the subjective evaluation of the participants' health condition and their lifestyle before cancer diagnosis and at present. The content and face validity of the questionnaire was evaluated by sociologists and psychologists, and was then piloted with a group of 30 women with the aim of checking the feasibility and understanding of the questionnaire.

The second questionnaire was the HBI developed by Juczyński [18]. This includes 24 statements describing different health behaviour categorised according to 4 factors: (1) proper nutritional habits [PNH], (2) preventive behaviours [PB], (3) health practices [HPs], and (4) positive mental attitude [PMA]), as enacted by the participants in the 12 months prior to data collection. The PNH dimension includes, above all, the kind of the food eaten (e.g. whole wheat bread, vegetables and fruit); the PBs dimension concerns obeying health recommendations, and acquiring information about health and disease; the HPs also include everyday habits related to sleep and recreation or physical activity. Finally, the PMA dimension includes the ability to avoid strong emotions, stress, tensions, or depressing situations. Conceptually, HBI includes 3 main behaviours [18]: (1) behaviours that are known to decrease or increase the risk of disease; (2) behaviours undertaken from the conviction that they contribute to health maintenance or to a reduction in the threat of disease; and (3) behaviours connected with obeying medical recommendations. The $\mathrm{HBI}$ has been validated with healthy and ill adults with good psychometric properties [18].

Using a five-point scale, study participants were invited to mark how often they enacted the health behaviours listed in the questionnaire: 1 - almost never; 2 - rarely; 3 - from time to time; 4 - often; 5 - almost always. The values marked by respondents were counted to obtain the overall indicator of health behaviour intensification; thus, scores ranged from 24-120. The higher the scores, the higher the increase in $\mathrm{HB}$. The overall BHI was then converted to standardised values - sten (from 1-10). The results ranged from 1-4 sten (low HBI), 5-6 sten (average HBI), 7-10 sten (high HBI). These were calculated for each dimension.

The questionnaires were presented to the eligible participants with an information sheet describing the study aims and assurance of anonymity. Each participant was given an informed consent declaration to read and sign. The average time to complete the survey was not longer than five minutes.

The collected data underwent statistical analyses using the IBM SPSS Statistics, version 21. With the use of the ShapiroWilk's test, each continuous variable was analysed according to the consistency of its distribution with the standard distribution. The variable distribution was also evaluated on the basis of a histogram. All of the variables turned out to be consistent with the standardised distribution, therefore the analysis was conducted with the use of the parametric methods. Descriptive analyses were performed to evaluate frequencies, proportions, averages, and standard deviations $(\mathrm{SD} ; \pm)$. To evaluate the differences between 2 independent groups, the one-way analysis of variance (ANOVA) was performed with the post-hoc test (multiple comparisons were conducted with the use of Turkey's test). The level of significance $\mathrm{p}<0.05$ was applied.

\section{RESULTS}

Participants. The surveyed women were aged between 40 and 85 with the average age being $57.4 \pm 8.6$. The majority were educated to secondary school level $(44 ; 46.3 \%)$, were living in a city at the time of the survey $(71 ; 74.7 \%)$, and were married (49;51.7\%). Their detailed socio-demographic features are presented in the Table 1.

Health notion, prevention, and health self-evaluation. The meanings that participants gave to the notion of health differed and the most frequent description was "well-being", as rshown in Table 2.

The majority of women $(75 ; 78.9 \%)$ reported that they led a healthy lifestyle, whereas 1 in $5(20 ; 21.1 \%)$ did not. Almost half of the respondents $(40 ; 42.1 \%)$ stated that before the cancer diagnosis they did not self-examine their breasts, and almost 1 in 3 participants $(26 ; 27.4 \%)$ reported that they did self-examine from time to time. Only 1 in 5 (19; $20.0 \%)$ stated that they self-examined their breasts once a month.

The majority $(74 ; 77.8 \%)$ answered that they undertook health checks according to the doctor's recommendations, whereas 11 participants (11.6\%) had health checks once a year. Among the respondents there were 10 women (10.6\%) who 
Table 1. Socio-demographic data of the surveyed women

\begin{tabular}{|c|c|c|}
\hline Variables & $\mathrm{N}$ & $\%$ \\
\hline \multicolumn{3}{|l|}{ Age } \\
\hline$<50$ & 13 & 13.7 \\
\hline $50-59$ & 43 & 45.3 \\
\hline $60-69$ & 32 & 33.7 \\
\hline$>70$ & 7 & 7.4 \\
\hline \multicolumn{3}{|l|}{ Education } \\
\hline Elementary & 3 & 3.2 \\
\hline Vocational & 15 & 15.8 \\
\hline Secondary & 44 & 46.3 \\
\hline Bachelor's degree & 11 & 11.6 \\
\hline Master's degree & 22 & 23.2 \\
\hline \multicolumn{3}{|l|}{ Place of living } \\
\hline City & 71 & 74.7 \\
\hline Rural area & 24 & 25.3 \\
\hline \multicolumn{3}{|l|}{ Marital status } \\
\hline Married & 49 & 51.7 \\
\hline Divorced & 14 & 14.7 \\
\hline Unmarried & 14 & 14.7 \\
\hline Widow & 18 & 18.9 \\
\hline
\end{tabular}

Table 2. The notion "health" as understood by women after mastectomy

\begin{tabular}{llc}
\hline Understanding of the notion "health" & $\mathrm{N}$ & $\%$ \\
\hline Well-being & 33 & 34.7 \\
\hline Lack of disease & 27 & 28.4 \\
\hline Mental fitness & 16 & 16.8 \\
\hline Physical fitness & 14 & 14.7 \\
\hline The most important value in life & 12 & 12.6 \\
\hline Overall & 95 & 100.0
\end{tabular}

had irregular health checks, i.e., dependent on the occurrence of worrying symptoms.

Participants' self-evaluation of health was good for the majority $(82 ; 83.3 \%)$. The remaining participants (13; $13.7 \%)$ reported satisfactory health. None of the respondents evaluated their health as very good or as bad.

Health behaviours. The overall HBI, on average, was 85.7; SD 12.7 (5.8; SD 1.7 sten) out of 24-120. The participants' range of scores varied from 44 (1 sten) to 116 (10 sten). Health practices (HPs), related to sleep and recreation or physical activity, obtained the highest score (average 3.75; SD 1.59) and were the highest HBs among the women surveyed (Tab. 3). The $\mathrm{PB}$ dimension, such as obeying health recommendations and acquiring information about health and disease, was second in terms of averages, whereas PNH and PMA were, on average, similar in their scores.

The bivariate analysis of HBI and age, education, place of residence, and marital status is presented in Table 4. There was no significant association between HBI, age, level of education, and place of residence ( $\mathrm{p}>0.05)$. Married women and widows reported higher HBI than the unmarried $(\mathrm{p}<0.05)$.

A bivariate analysis was then performed between the dimensions of HBI and participants' individual variables
Table 3. The overall health behaviour indicator for each dimension by Juczyński Questionnaire

\begin{tabular}{lll}
\hline Behaviour dimension* & A & SD \\
\hline Proper nutritional habits (PNH) & 3.51 & 0.67 \\
\hline Prophylactic behaviours (PB) & 3.66 & 0.69 \\
\hline Positive mental attitude (PMA) & 3.51 & 0.57 \\
\hline Health practices (HPs) & 3.75 & 1.59 \\
\hline
\end{tabular}

* Proper nutritional habits (PNH) described in the questionnaire by questions: (-) I eat a lot of vegetables and fruits; (-) I limit the consumption of products such as animal fats and sugar; $(-)$ I care about proper nutrition; (-) I avoid eating food with preservatives; (-) I avoid salt and highly salted food; l eat whole wheat bread.

Prophylactic behaviours (PB) described in the questionnaire by questions: (-) I avoid colds, (-) I have the emergency service telephone numbers noted down; (-) I adhere to the medical recommendations resulting from checkups; (-) I regularly apply for medical examinations; (-) I'm trying to find out how others avoid diseases; (-) I am trying to get medical information and understand the causes of health and illness.

Positive mental attitude (PMA) described in the questionnaire by questions: (-) I take seriously the instructions of people who are concerned about my health; (-) I avoid situations which depress me; (-) I try to avoid too strong emotions, stress and tensions; $(-)$ I have friends and settled family life; (-) I avoid such feelings as anger, anxiety and depression; (-) I think positively. Health practices (HPs) described in the questionnaire by questions: (-) I rest enough; (-) I avoid overworking; (-) I control my body weight; (-) I sleep enough; (-) I'm limiting smoking; (-) I avoid excessive physical exertion.

Table 4. Health Behavior Indicator scores and individual variables

\begin{tabular}{|c|c|c|}
\hline Variables & $A \pm S D$ & $P$ value \\
\hline \multicolumn{3}{|l|}{ Age } \\
\hline Below 50 & $82.3 \pm 14.5$ & \multirow{4}{*}{$\begin{array}{c}F=1.34 \\
d f=3.0 \\
p=0.266\end{array}$} \\
\hline $50-59$ & $84.0 \pm 13.4$ & \\
\hline $60-69$ & $88.0 \pm 10.0$ & \\
\hline Above 70 & $91.4 \pm 15.6$ & \\
\hline \multicolumn{3}{|l|}{ Education } \\
\hline Elementary & $76.0 \pm 19.5$ & \multirow{5}{*}{$\begin{array}{c}F=2.00 ; d f=4 \\
p=0.101\end{array}$} \\
\hline Vocational & $83.8 \pm 12.4$ & \\
\hline Secondary & $87.4 \pm 11.5$ & \\
\hline Bachelor's degree & $78.2 \pm 10.9$ & \\
\hline Master's degree & $88.4 \pm 14.2$ & \\
\hline \multicolumn{3}{|l|}{ Place of dwelling } \\
\hline City & $86.5 \pm 12.7$ & \multirow{2}{*}{$\begin{array}{c}t=1.08 ; d f=93 \\
p=0.28\end{array}$} \\
\hline Rural area & $83.2 \pm 12.8$ & \\
\hline \multicolumn{3}{|l|}{ Marital status } \\
\hline Married & $87.2 \pm 12.7$ & \multirow{4}{*}{$\begin{array}{c}F=3.58 ; d f=3 \\
p=0.017\end{array}$} \\
\hline Divorced & $83.6 \pm 12.5$ & \\
\hline Unmarried & $76.7 \pm 14.6$ & \\
\hline Widow & $89.8 \pm 7.9$ & \\
\hline
\end{tabular}

A - average; \pm SD - standard deviation

(Tab. 5). There was a significant difference in $\mathrm{PNH}$ with regard to the respondents' level of education $(\mathrm{p}=0.005)$. Women with higher education reported the highest score. With regard to the $\mathrm{PB}$ and marital status, statistically significant differences also emerged $(\mathrm{p}=0.017)$. The married and widowed participants reported a higher score than divorced and unmarried women. There were no statistically significant differences in the range of HBI regarding the place of residence and age $(\mathrm{p}>0.05)$. 
Table 5. Health behaviour dimensions and individual variables

\begin{tabular}{lcccc}
\hline Variables & $\begin{array}{c}\text { Proper } \\
\text { Nutritional } \\
\text { Habits } \\
(\mathrm{PNH})\end{array}$ & $\begin{array}{c}\text { Prophylactic } \\
\text { Behaviour } \\
(\mathrm{PB})\end{array}$ & $\begin{array}{c}\text { Positive } \\
\text { Mental } \\
\text { Attitude } \\
(\mathrm{PMA})\end{array}$ & $\begin{array}{c}\text { Health } \\
\text { Practices } \\
(\mathrm{HPS})\end{array}$ \\
\hline $\mathrm{A} \pm \mathrm{SD}$ & $\mathrm{A} \pm \mathrm{SD}$ & $\mathrm{A} \pm \mathrm{SD}$ & $\mathrm{A} \pm \mathrm{SD}$ \\
\hline
\end{tabular}

\begin{tabular}{|c|c|c|c|c|}
\hline Age & & & & \\
\hline Below 50 & $3.21 \pm 0.8$ & $3.46 \pm 0.9$ & $3.49 \pm 0.6$ & $3.53 \pm 0.6$ \\
\hline $50-59$ & $3.50 \pm 0.7$ & $3.62 \pm 0.7$ & $3.46 \pm 0.6$ & $3.76 \pm 2.3$ \\
\hline $60-69$ & $3.60 \pm 0.5$ & $3.73 \pm 0.6$ & $3.56 \pm 0.5$ & $3.78 \pm 0.4$ \\
\hline Above 70 & $3.76 \pm 0.6$ & $3.86 \pm 0.7$ & $3.64 \pm 0.6$ & $3.93 \pm 0.7$ \\
\hline$p$-value $(d f=3.0)$ & $\begin{array}{l}F=1.35 \\
p=0.263\end{array}$ & $\begin{array}{c}F=0.69 \\
p=0.559\end{array}$ & $\begin{array}{l}F=0.311 \\
p=0.817\end{array}$ & $\begin{array}{c}F=0.11 \\
p=0.954\end{array}$ \\
\hline \multicolumn{5}{|l|}{ Education } \\
\hline Elementary & $2.89 \pm 0.9$ & $3.0 \pm 0.9$ & $3.33 \pm 0.7$ & $3.44 \pm 0.8$ \\
\hline Vocational & $3.36 \pm 0.6$ & $3.53 \pm 0.6$ & $3.52 \pm 0.6$ & $3.55 \pm 0.6$ \\
\hline Secondary & $3.61 \pm 0.6$ & $3.75 \pm 0.7$ & $3.56 \pm 0.5$ & $3.64 \pm 0.5$ \\
\hline Bachelor's degree & $3.13 \pm 0.7$ & $3.42 \pm 0.7$ & $3.22 \pm 0.5$ & $3.24 \pm 0.4$ \\
\hline Master's degree & $3.69 \pm 0.7$ & $3.75 \pm 0.7$ & $3.59 \pm 0.6$ & $4.39 \pm 3.1$ \\
\hline$p$-value $(d f=4)$ & $\begin{array}{l}F=2.45 \\
p=0.052\end{array}$ & $\begin{array}{c}F=1.45 \\
p=0.220\end{array}$ & $\begin{array}{l}F=0.95 \\
p=0.430\end{array}$ & $\begin{array}{c}F=1.33 \\
p=0.260\end{array}$ \\
\hline \multicolumn{5}{|l|}{ Place of dwelling } \\
\hline City & $3.56 \pm 0.64$ & $3.7 \pm 0.68$ & $3.52 \pm 0.61$ & $3.63 \pm 0.58$ \\
\hline Rural area & $3.37 \pm 0.76$ & $3.52 \pm 0.73$ & $3.50 \pm 0.43$ & $4.1 \pm 3.01$ \\
\hline$p$-value $(d f=93)$ & $\begin{array}{c}t=1.17 \\
p=0.240\end{array}$ & $\begin{array}{c}t=1.06 \\
p=0.290\end{array}$ & $\begin{array}{l}t=0.163 \\
p=0.870\end{array}$ & $\begin{array}{c}\mathrm{t}=23.6 \\
\mathrm{p}=0.450\end{array}$ \\
\hline \multicolumn{5}{|l|}{ Marital status } \\
\hline Married & $3.58 \pm 0.71$ & $3.73 \pm 0.64$ & $3.59 \pm 0.58$ & $3.94 \pm 2.1$ \\
\hline Divorced & $3.35 \pm 0.72$ & $3.69 \pm 0.73$ & $3.47 \pm 0.5$ & $3.41 \pm 0.65$ \\
\hline Unmarried & $3.18 \pm 0.67$ & $3.13 \pm 0.84$ & $3.17 \pm 0.66$ & $3.29 \pm 0.78$ \\
\hline Widow & $3.70 \pm 0.39$ & $3.84 \pm 0.51$ & $3.61 \pm 0.38$ & $3.84 \pm 0.46$ \\
\hline $\mathrm{p}$-value $(d f=3)$ & $\begin{array}{l}F=2.14 \\
p=0.101\end{array}$ & $\begin{array}{c}F=3.57 \\
p=0.017\end{array}$ & $\begin{array}{c}F=2.21 \\
p=0.090\end{array}$ & $\begin{array}{c}F=0.85 \\
p=0.850\end{array}$ \\
\hline
\end{tabular}

A - average; F - ANOVA Test; $d f$ - degree of freedom; SD - standard deviation

\section{DISCUSSION}

Participants. A group of postmenopausal women who had undergone mastectomy at least 3 months prior to the survey participated in the study. Pacian et al. [3] previously conducted a similar study in Poland, surveying 104 Polish women after radical mastectomy, and Kurowska et al. [5] studied 98 women after mastectomy. Kachaniuk et al. [19] conducted research involving 212 women after mastectomy and compared their health behaviours with those of a control group of 354 healthy women. All these studies used, among others, the HBI tool developed by Juczyński [18]. However, the studies mentioned above focused on the $\mathrm{HB}$ of women after mastectomy without taking into account their menopausal state, therefore only a limited comparison with the current study is possible.

Health notion, prevention, and health self-evaluation. The concept of health can be understood as "lack of disease, "species' standard", "functioning of the body", "adaptability", "physical, mental, social and even spiritual well-being" [20] and [21]. Parson's conception of health, approved in in 1978 in Alma-Ata, Kazakhstan, assumes that health is an individual's ability to perform social roles and tasks resulting from these roles, gave health the status of a fundamental human right $[20,21]$. On the other hand, the World Health Organization formulated a holistic and positive notion of health, understood as biological, mental, and social wellbeing, rather than merely the lack of disease or disability [20-22]. Therefore, at times the notion of "health" is replaced by "well-being", which indicates a person's ability to function in an environment, and their adaptability to stress situations, positive as well as negative [20-22].

Undoubtedly, breast cancer diagnosis and its treatment constitute a stressful situation for a woman, threatening their health in a broader sense. In accordance with the findings of the presented study, the majority of participants considered "health" as "well-being", and every third woman stated that health meant the "lack of a diagnosed disease". Less often, "health" was considered as physical and mental activity. According to the literature, health is perceived as the greatest value in life: value which is instrumental in nature in that it is a means to achieve other values $[21,23]$. Thus, it is surprising that among women after mastectomy, only a few (12.4\%) were of this opinion. Possibly for postmenopausal women experiencing cancer and painful surgery - both of which are life experiences accompanied by uncomfortable physical and psychosocial feelings - the meaning of "health" is concrete rather than abstract. The notion of "well-being" seems to have a broader meaning that covers all aspects of subjective feelings of being healthy, such as physical and psychosocial, and not only a lack of pain and sickness.

The majority of participants evaluated their health as good and stated that they led healthy lifestyles. Given that they were all active members of the Amazon Women Association in Lublin, and were therefore likely to be healthier than many other women, and who may also encourage other women to undertake healthy lifestyles, future studies should avoid this potential selection bias by adopting a large sample that also includes women who are not involved with such associations.

Health behaviour. The overall HBI average was 85.7, SD 12.7 (5-6 sten). In validating the HBI tool, Juczyński [18] involved a group of 496 adults with different health conditions and the average score was 81.82 (14.16 SD). However, among others, there was also group of women experiencing menopause $(n=50)$ whose level of HBI was higher -85.98 (12.7 SD), therefore in line with the findings of the current study. The findings were also in line with Pacian et al. [3] who included 104 Polish women after radical mastectomy and with Kurowska et al. [5] whose study included 98 women after mastectomy. On the other hand, Kachaniuk et al. [19] conducted their research with the use of a control group. They examined 212 women after mastectomy and 354 healthy women, reporting an overall intensification of health behaviours in both groups, although slightly higher in the first group than in the healthy women. Patients after breast cancer diagnosis, during treatment, and in the period of remission, placed a greater emphasis on improving their lifestyles: they reported trying to avoid behaviours that were threatening to health and implementing pro-health behaviours [3, 5-13].

The findings of this study show that the highest scored HBI was related to HPs (mean=3.75), followed by the dimension of PB (mean=3.66). HPs data was higher than reported by Juczyński $(3.32 ; 0.85$ SD) for the general population and higher 
than their sub-group of women experiencing menopause $(3.43 ; 0.62 \mathrm{SD})[18]$. In the PB dimension, higher values also emerged with respect to those documented by Juczyński (3.42;0.78 SD for all groups), but lower when compared with those that emerged among women experiencing menopause (3.71; $0.74 \mathrm{SD})$. With regard to the $\mathrm{PNH}$ dimension, the scores were higher $(3.51 ; 0.67 \mathrm{SD})$ than those obtained by Juczyński (3.22; $0.75 \mathrm{SD})$, and similar when compared only with women experiencing menopause $(3.55 ; 0.75$ SD). Finally, the results obtained in the PMA dimension (3.51; 0.57 SD) were similar to those reported by Juczyński (3.52; 0.66 SD) and lower when compared with women in the menopausal state $(3.64 ; 0.70 \mathrm{SD})$.

In previous Polish research, the highest average was obtained for the PB dimension (mean=3.72), followed by PMA and HPs (with the same mean - 3.53, each) [3]. The participants in the presented study tried to eat healthily (NP, mean $=3.51$ ); previously the authors reported both higher $($ mean=3.55) [19] and lower values (mean=3.01) [3]. Moreover, researchers have observed that women after mastectomy were characterised by high HBI intensification in the PBs dimension (mean=3.62), followed by HPs (mean=3.61) and PMA (mean=3.60) [19]. Although there are slight differences between the presented findings and those of previous studies, which may have limited clinical relevance, the available literature reports that breast cancer diagnosis and the surgical treatment that follows is a traumatic experience $[1,5,6,8$, $9,12,13,24]$. Specifically, Ogińska-Bulik and ZadwornaCieślak [24] in their studies measuring correlations between traumatic experiences and health behaviours, documented that women who had traumatic experiences are characterised by higher HBI, mainly prophylactic in nature.

The level of education has been documented as a factor shaping the $\mathrm{HB}$ of Polish people [25, 26, 27]. While conducting research among adults, Nowicki and Ślusarska [27] documented that the overall HBI in people with higher education was higher than in those with lower education. Similar results were obtained by Sygit-Kowalkowska [26] when studying the $\mathrm{HB}$ of the residents of nursing homes and students of the Third Age University. However, no such differences emerged in the findings of the current study. It is possible that this is the consequence of an association with similar people suffering from health problems, and that preventive strategies and behaviour may be discussed in groups or in couples through the different initiatives offered to the members, and may thus attenuate the differences in health literacy and the consequent behaviours.

However, married women and widows were characterised by higher overall HBI than other women, as well as having higher indicators in the category of prophylactic behaviours. In contrast, unmarried women reported the lowest HBI average. Given that no previous literature was found, no comparison is possible; however, a correlation between marital status and health behaviours has been observed in other studies [28]. Whereas married and widowed women may be motivated to intensify health behaviour because of family commitments, unmarried women may be less motivated and supported by family members, and therefore may need more support.

Study limitations. Several limitations affect this study: among others, selection bias, the lack of data regarding the disease and the treatments, as well as lack of data regarding previous health behaviours and health notions. These limitations suggest the need to develop further studies that include a large group of participants, a control group composed of postmenopausal healthy women, and the collection of more clinical data. In addition, there is a need to develop international studies aimed at describing differences, if any, in health behaviour as influenced by culture, the women's status, as well as by their health histories. I would also be worthwhile to develop studies concerning the more objective indicators of health behaviours - BMI or WHR.

\section{CONCLUSIONS}

Despite the limitations, the presented findings suggest that postmenopausal women who have undergone mastectomy consider health condition mainly in terms of "well-being" and the majority believed that they led a healthy lifestyle. Health Behavior Indicators were higher for this group of women, which may suggest that mastectomy at the postmenopausal state enforces pro-healthy HBs. Married and widowed women enacted higher health behaviours, whereas those who were unmarried reported lower scores, thus suggesting the requirement for their needs to be carefully assessed, as well as to receive tailored supportive interventions.

\section{Acknowledgements}

The authors express their gratitude to all the women who agreed to participate in this study.

\section{REFERENCES}

1.Pawlik M, Karczmarek-Borowska B. Acceptance of breast cancer in women after mastectomy. PrzMedUniw Rzesz 2013; 2: 203-211.

2. Smaga A, Mikułkowska M, Komorowska A, Falkiewicz B, Grygelewicz J. Rak piersi w Polsce - leczenie to inwestycja. Raport Polskiego Towarzystwa Badań nad Rakiem Piersi, Sequence HC Partners Sp. z.o.o., Lazarski University of Warsaw 2014, 2-8.

3. Pacian A, Kulik TB, Skórzyńska H, Chruściel P, Stefanowicz A, Dąbrowska A. Health factors among women after mastectomy. Menopause Rev 2013; 5: 392-398.

4. Vera-Llonch M, Weycker D, Glass A, Gao S, Borker R, Qin A, et al. Healthcare costs in women with metastatic breast cancer receiving chemotherapy as their principal treatment modality. BMC Cancer 2011; 11: 250 .

5. Kurowska K, Kalawska H. Health behaviours and health locus of control in women after mastectomy. CurrGynecolOncol 2013; 11: 115-124.

6. Bragado-Alvarez C, Herenadez-Lloreda MJ, Sanchez-Bernardos L, Herrera de la Muela M, Gomez-Campelo P. Exploring psychosocial correlates of breast reconstruction post- mastectomy in a sample of Spanish women. Ann Psychiatry Ment Health 2016; 4: 1-5.

7. Neto SM, Moreira JR, Resende V, Ferreira LM. Physical activity in women undergoing mastectomy and breast reconstruction. Rev Bras Cir Plast 2012; 27: 556-561.

8. Bellizzi KM, Blank TO. Predicting posttraumatic growth in breast cancer survivors. Health Psychol 2006; 25: 47-56.

9. Bussel V, Naus M. A longitudinal investigation of coping and posttraumatic growth in breast cancer survivors. J PsychosocOncol 2010; 28: 61-78.

10. Heng Y, Shariff ZM, Kandiah M, MunChY, Othman Z, Saibul N, et al. Weight changes and lifestyle behaviors in women after breast cancer diagnoisis: a cross - sectional study. BMC Public Health 2011; 11: 309-318.

11. Grameling R, Lash TL, Rothman KJ, Cabral HJ, Silliman R, Roberts M, et al. Family history of later-onest breast cancer, breast health behavior and invasive breast cancer among postmenopausal women; a cohort study. Breast Cancer Res 2010; 12: R82.

12. Ominyi JN, Nwodom MU. Psychosocial impact of mastectomy and breast reconstruction. Int J Sci Res 2012; 3: 551-556. 
13. Steinhilper L, Geyer S, Sperlich S. Health behavior change among breast cancer patients. Int J Public Health 2013; 58: 1-14.

14. Yaw YH, Shariff ZM, Kandiah M, MunChY, Yusof RM, Othman Z, et al. Weight changes and lifestyle behaviors in women after breast cancer diagnosis: a cross-sectional study. BMC Public Health 2011; 11: 309.

15. Iacolo EK, Makari-Judson G, Mertens WC, Katz D, Sturgeon SR, Bigelow C, et al. Perceive Recurrence Risk and Health Behavior Change among Breast Cancer Survivors. J Womens Health Gyn 2014; 1: 1-8.

16. McKenzie F, Ferrari P, Freisling H, Chajès V, Rinaldi $S$, de Batlle J, et al. Healthy lifestyle and risk of breast cancer among postmenopausal women in the European Prospective Investigation into Cancer and Nutrition cohort study. Int J Cancer 2015; 136: 2640-2648.

17. Thomson CA, McCullough ML, Wertheim BC, Chlebowski RT, Martinez ME, Stefanick ML, et al. Nutrition and physical activity cancer prevention guidelines, cancer risk, and mortality in the Women's Health Initiative. Cancer Prev Res2014; 7: 42-53.

18. Juczyński Z. Narzędzia pomiaru w promocji i psychologii zdrowia. Wydanie II. Pracownia Testów Psychologicznych, Warszawa 2009, $110-116$.

19. Kachaniuk H, Stanisławek A, Bartoszek A, Kocka K, SzadowskaSzlachetka Z, Charzyńska-Gula M. An analysis of selected health behaviours of women as Brest cancer risk factors. Menopause Rev 2013; 6: 453-458.
20. Domaradzki J. On the definitions of health and disease. Folia Med Lodz 2013; 40: 5-29.

21. Ślusarska B, Dobrowolska B, Zarzycka D. Metatheoretical context of health behavior in health paradigms. ProblHigEpidemiol 2013; 94: 667-674.

22. Gruszczyńska M, Bąk-Sosnowska M, Plinta R. Health-related behaviors as an essential part of human life activities. Attitude of Poles towards their own health. Hygeia Public Health 2015; 50: 558-565.

23. Marcum JA. An introductory philosophy of medicine. Humanizing modern medicine. Springer, Dordrecht, 2008.

24. Ogińska-Bulik N, Zadworna-Cieślak M. Role of posttraumatic growth in manifesting health behaviors in the group of people in late adulthood period. Pol Forum Psychol 2014; 19: 247-253.

25. Janowski M, Rasińska R. Selected health behaviours of health care professionals. Pielęg Pol 2015; 2: 164-169.

26. Sygit-Kowalkowska E. The health behavior of people in late adulthoodsociodemographic correlations and differences between social environments. Ann Acad Med Stetin 2013; 59: 103-113.

27. Ślusarska B, Nowicki G. Health behaviours in prophylaxis of cardiovascular diseases among occupationally active population. ProblHigEpidemiol 2010; 91: 34-40.

28. Yim HJ, Park HA, Kang JH, Kim KW, Cho YG, Hur YI, et al. Marital Status and health behavior in middle-aged Korean adults. Korean J Fam Med 2012; 33: 390-397. 